\title{
Models for reproducing the damage scenario of the Lorca earthquake
}

\author{
A. Rivas-Medina - S. Martínez-Cuevas · L. E. Quirós · \\ J. M. Gaspar-Escribano - A. Staller
}

\begin{abstract}
A damage scenario modelling is developed and compared with the damage distribution observed after the 2011 Lorca earthquake. The strong ground motion models considered include five modern ground motion prediction equations (GMPEs) amply used worldwide. Capacity and fragility curves from the Risk-UE project are utilized to model building vulnerability and expected damage. Damage estimates resulting from different combinations of GMPE and capacity/fragility curves are compared with the actual damage scenario, establishing the combination that best explains the observed damage distribution. In addition, some recommendations are proposed, including correction factors in fragility curves in order to reproduce in a better way the observed damage in masonry and reinforce concrete buildings. The lessons learned would contribute to improve the simulation of expected damages due to future earthquakes in Lorca or other regions in Spain with similar characteristics regarding attenuation and vulnerability.
\end{abstract}

Keywords Lorca earthquake · Seismic scenario · Vulnerability · Damage

\section{Introduction}

A significant number of regional seismic hazard risk studies have been carried out in Spain during the past 10 years, in the frame of projects such as RISMUR (Benito et al. 2008), SISMOSAN (Benito et al. 2010) and RISNA (Gaspar-Escribano et al. 2011) among others. These regional studies have been implemented on account of the legal requirement mandating the regional civil defence services to draft regional seismic emergency plans. At the present time, by the same basic directive, many municipalities of those regions are bound to carry out urban seismic risk studies.

Some seismic hazard/risk expert working groups are currently developing those studies in Spain. They find a challenge to reproduce earthquake scenarios based on observed data due 
to their limited availability and range of applicability (Benito and Gaspar-Escribano 2007). Actually, the low-to-moderate seismic activity observed in Spain leads to a relative scarcity of sufficiently strong events for providing empirical data that can be used to constraint and reproduce local earthquake scenarios. These scant data include ground motion records of high magnitude events as well as damage distribution estimates of typical Spanish building typologies for different input ground motions, etc. For example, only two earthquakes with intensity VII or higher have been recorded in Spain in the past 30 years; the first one occurred in La Paca, Murcia on 29th January, 2005 (Benito et al. 2007) and the second one occurred in Lorca, Murcia on 11th May, 2011.

In relation with the scarcity of strong ground motion data at Spanish sites, the seismic characterization and the seismic hazard assessment of Spanish sites are carried out making use of empirical GMPEs developed for other areas of the world with a similar tectonic regime. In this context, the earthquake occurred in Lorca on the 2011, May 11th entails a fair amount of information that can be used to contrast modern GMPEs developed elsewhere as well as capacity and fragility curves to this specific location. Hence, a calibration of the different models that are being applied in Spain with the data compiled in Lorca is carried out in this paper. This work involves the following tasks:

- Ground motion estimation including seismic source and attenuation models; considering different GMPEs found in the literature that will be contrasted with the recorded earthquake data.

- Seismic vulnerability modelling of the building stock of Lorca for damage assessment, using empirical models, as provided by the literature, which are being applied in Spain.

- Several damage scenarios, one for each selected GMPE, are developed in an attempt to replicate the 2011 Lorca scenario.

- Comparisons between modelled and observed damage trends are accomplished, pointing out the resulting similarities and differences.

\section{Simulation of strong ground motion for the Lorca 2011 (Mw 5.2) earthquake}

To reproduce the expected strong motion observed in Lorca, earthquake source parameters and site effects need to be characterized consistently with the selected GMPEs. Details on earthquake source characteristics and soil parameters are given below, together with the GMPEs used and the resulting ground motion distribution:

\subsection{Source and site characterization}

The first step to model the strong motion of the 2011, Mw 5.2 Lorca earthquake is the definition of the seismic source. This includes the assessment of fault motion angles and the geometry. Slip and rake angles, representing an inverse faulting mechanism, as well as the vertexes of the rectangular rupture plane adopted are taken from the source model presented by Santoyo (2013) (Table 1).

Given the location of the rupture, several distance parameters are calculated as demanded by the GMPEs used (Fig. 1). Thus, different distances are considered: rupture (Rrup), JoynerBoore $(\mathrm{Rjb})$ and normal distance from the site to the line containing the surface projection of the upper boundary of the rupture $(\mathrm{Rx})$. All of them are computed in a grid of sites covering the built-up area of Lorca (equidistance of $50 \mathrm{~m}$ for the nodes of the grid).

The characterization of site conditions differs within the study region. Soil conditions are typically represented by the average shear wave velocity in the uppermost $30 \mathrm{~m}$ of the soil 
Table 1 Parameters of the rupture surface corresponding to Lorca earthquake: coordinates of the rectangular source (R1, R2, R3 and R4), azimuth and dip

\begin{tabular}{llll}
\hline & Long. $\left(^{\circ}\right)$ & Lat. $\left(^{\circ}\right)$ & Prof. $(\mathrm{m})$ \\
\hline R1 & -1.6752 & 37.7101 & -3661.7 \\
R2 & -1.7146 & 37.6921 & -3661.7 \\
R3 & -1.7276 & 37.7099 & -6938.3 \\
R4 & -1.6882 & 37.7279 & -6938.3 \\
Stike & $240^{\circ}$ & & \\
Dip & $54^{\circ}$ & & \\
\hline
\end{tabular}

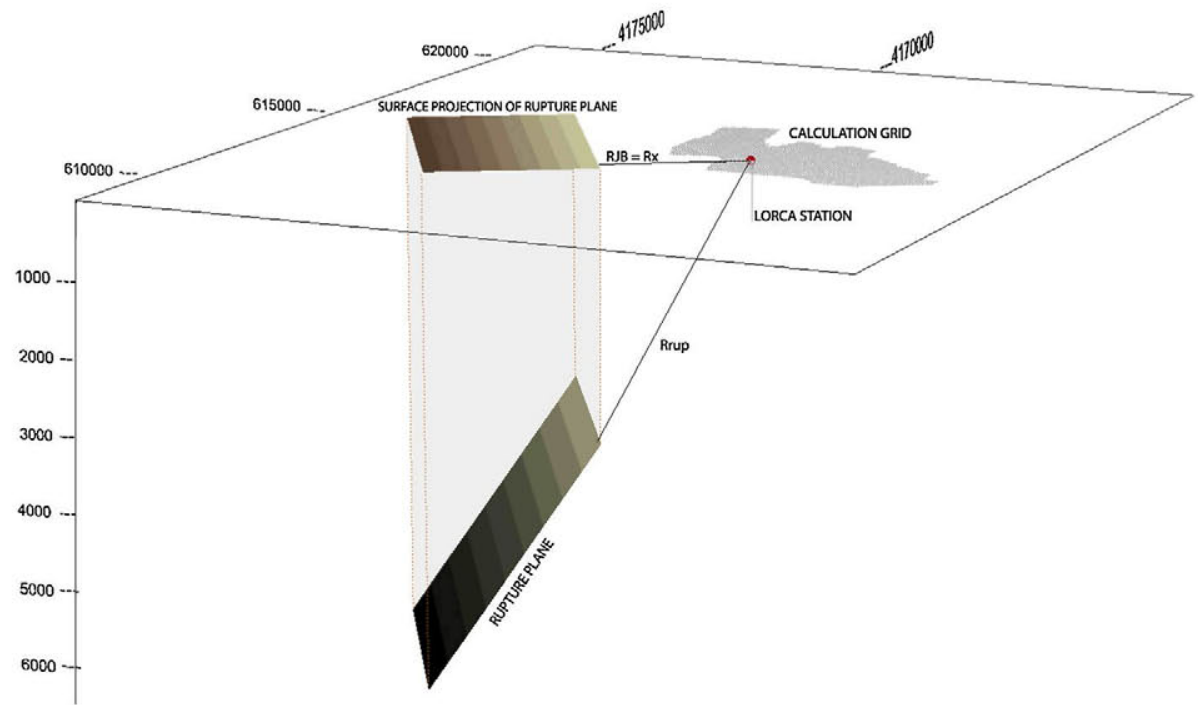

Fig. 1 Map showing the surface projection of the rupture plane, the location of Lorca and the calculation grid considered

column (Vs30 value). The Vs30 map of Navarro et al. (2013), which is based on in situ measurements conducted in Lorca, is considered as input data in this work. The Vs30 values obtained range from 180 to over $800 \mathrm{~m} / \mathrm{s}$.

\subsection{Selection of GMPEs for ground motion modeling}

A GMPE is used to predict the ground motion expected at a given site caused by an earthquake event defined by, at least, its magnitude, source-to-site distance and other variables such as the style of faulting, soil conditions at the site, etc. In this work, the predicted ground motion parameters are the peak ground acceleration (PGA) and the spectral accelerations $\mathrm{SA}(\mathrm{T})$ for periods T of $0.1,0.2,0.3,0.4,0.5,1.0$ and $2.0 \mathrm{~s}$.

A goal of this study is to reproduce the ground motion recorded in Lorca due to the 2011 earthquake, Mw 5.2. The GMPE that may reproduce with the greatest detail possible the characteristics of the seismic source and the site effects will be selected for this purpose. In this regard, the Next Generation Attenuation (NGA) models are good candidates as they are developed with a large database and contain many variables representing fault parame- 
ters (focal mechanism, dip angle, depth to top of rupture) and site effects (a non-linear soil amplification term based on quantitative estimates of Vs30 and basin depth parameters). Among these models, the ones proposed by Abrahamson and Silva (2008), Boore and Atkinson (2008), Campbell and Bozorgnia (2008) and Chiou and Youngs (2008) contain a more detail description of the site factor. Models AS08 and CY08 stand out due to their special attempt at modelling the near field ground motion by considering the hanging wall effect and three different source-to-site distance parameters. The BA08 model is simpler than the others and it has been recently corrected for low magnitudes (Atkinson and Boore 2011). This updated version is the one used in this study. The CY08 model has also been modified for low magnitudes (Chiou et al. 2010) but in this case the changes have been made only for PGA, SA $(0.3 \mathrm{~s})$ and SA $(1.0 \mathrm{~s})$. As the aim of this study is to use the full spectrum calculated from several spectral accelerations, the modified version of CY08 is not suitable for this work.

Other models being used for the same purpose include the one developed with European data, published in Akkar and Bommer (2010), recommended for applications in Europe and used in several studies (Delavaud et al. 2012a, b; Beauval et al. 2012). Although this model does not allow the determination of the rupture plane in such a specific way as some NGA models, as it only contains style of faulting categories and not specific angle values, they do enable to single out some differences between rupture mechanisms, such as in the BA08 model.

The five models finally used in this study to simulate the ground motion scenario for the Lorca 2011 earthquake are shown in Table 2. The selected models consider the soil effect in different ways. The NGA GMPEs include the value of the Vs30 directly as a variable in the equation, allowing the introduction of that value in a continuous way. However, AB10 distinguishes three types of soil taking a discrete variable. In this work, five soil types are considered, in accordance with the EC8 classification.

\subsection{Results of the simulation in terms of PGA and response spectra}

The five GMPEs previously selected are used in order to estimate the PGA and SA(T) for $\mathrm{T}=0.1,0.2,0.3,0.4,0.5,1.0$ and $2.0 \mathrm{~s}$ applying the source conditions of the 2011 Lorca earthquake and taking into account site effects in the affected area. Figure 2 shows a comparison between the response spectra derived from the strong motion record at the Lorca station (see Cabañas et al. 2013 for details) and the ones predicted by the five selected GMPEs (giving in this case the median plus/minus one sigma). The figure shows that the predicted spectrum is quite similar (or slightly higher) to the recorded one for $\mathrm{T}<0.3 \mathrm{~s}$, while that is exceeded by the actual spectrum for $\mathrm{T}<0.3 \mathrm{~s}$. In general, for the long period range, the recorded $\mathrm{SA}(\mathrm{T})$ fit quite well the median plus one sigma predicted spectra.

The PGA simulation for the entire built-up area of Lorca is presented in Fig. 3. Maximum accelerations estimated by AS08, CY08 and CB08 GMPEs range between 0.2 and $0.3 \mathrm{~g}$, while those estimated through $\mathrm{AB} 10$ and $\mathrm{BA} 08$ equations are lower, in the range $0.12-0.23 \mathrm{~g}$. The amplification factor contained in the NGA models presents remarkable differences between the soil categories A and B1 and the other categories. However, they do not show a clear difference in the amplification for the Vs30 values corresponding to soil type D (the lowest Vs30 values in the study area). The AB 10 model shows a clear site effect on D type soils as well as on soils comprised between the B1 and B2 types. 
Table 2 Description of the GMPEs used for reproducing the input ground motion scenario of the 2011 Lorca earthquake (Mw 5.2)

\begin{tabular}{|c|c|c|c|c|c|c|c|c|c|}
\hline Name & Code & Mw range & R type & $\mathrm{R}(\mathrm{Km})$ range & $\begin{array}{l}\text { Predicted } \\
\text { ground motion } \\
\text { parameter }\end{array}$ & $\begin{array}{l}\text { Site classification } \\
\text { based on Vs } 30\end{array}$ & $\begin{array}{l}\text { Style of fault- } \\
\text { ing }\end{array}$ & $\begin{array}{l}\text { Horizontal } \\
\text { component } \\
\text { definition }\end{array}$ & $\begin{array}{l}\text { Region(s) of } \\
\text { data }\end{array}$ \\
\hline $\begin{array}{l}\text { Chiou and } \\
\text { Youngs } \\
(2008)\end{array}$ & CY08 & $4.27-7.9$ & Rrup & $0.2-70$ & $\begin{array}{l}\mathrm{SA}(0.01) \text { to } \\
\mathrm{SA}(10), \\
\text { PGA, PGV }\end{array}$ & Cont. function & $\mathrm{N}, \mathrm{R}, \mathrm{S}$ & GMRotI50 & California, Taiwan \\
\hline $\begin{array}{l}\text { Abrahamson } \\
\text { and Silva } \\
(2008)\end{array}$ & AS08 & $5.0-8.5$ & Rrup & $0-200$ & $\begin{array}{l}\text { SA }(0.01) \text { to } \\
\text { SA(10), } \\
\text { PGA, PGV }\end{array}$ & Cont. function & $\mathrm{N}, \mathrm{R} / \mathrm{T}, \mathrm{S}$ & GMRotI50 & California, Taiwan \\
\hline $\begin{array}{l}\text { Campbell and } \\
\text { Bozorgnia } \\
(2008)\end{array}$ & CB08 & $4.27-7.9$ & Rrup & $0.07-200$ & $\begin{array}{l}\mathrm{SA}(0.01) \text { to } \\
\mathrm{SA}(10), \\
\text { PGA, PGV }\end{array}$ & Cont. function & $\mathrm{N}, \mathrm{R}, \mathrm{S}$ & GMRotI50 & California, Taiwan \\
\hline $\begin{array}{l}\text { Boore and } \\
\text { Atkinson } \\
(2008)\end{array}$ & BA08 & $4.27-7.9$ & Rjb & $0-280$ & $\begin{array}{l}\mathrm{SA}(0.01) \text { to } \\
\text { SA(10), } \\
\text { PGA, PGV }\end{array}$ & Cont. function & $\mathrm{N}, \mathrm{R}, \mathrm{S}, \mathrm{U}$ & GMRotI50 & California, Taiwan \\
\hline $\begin{array}{l}\text { Akkar and } \\
\text { Bommer } \\
(2010)\end{array}$ & $\mathrm{AB} 10$ & $5.0-7.6$ & $\mathrm{Rjb}$ & $0-99$ & $\begin{array}{l}\mathrm{SA}(0.05) \text { to } \\
\mathrm{SA}(3), \mathrm{PGA}, \\
\text { PGV }\end{array}$ & 3 classes & $\mathrm{N}, \mathrm{R} / \mathrm{T}, \mathrm{S}$ & GMEAN & Europe and Middle Easi \\
\hline
\end{tabular}

$R$ distance, RUP rupture, RJB Joyner-Boore, cont. function continuous function of $v \mathrm{~S} 30$, sof style of faulting, $N$ normal, $R$ reverse, $T$ thrust, $U$ undefined, $G M E A N$ geometric mean, GMRotI50 ground motion definition used in the PEER NGA Project 

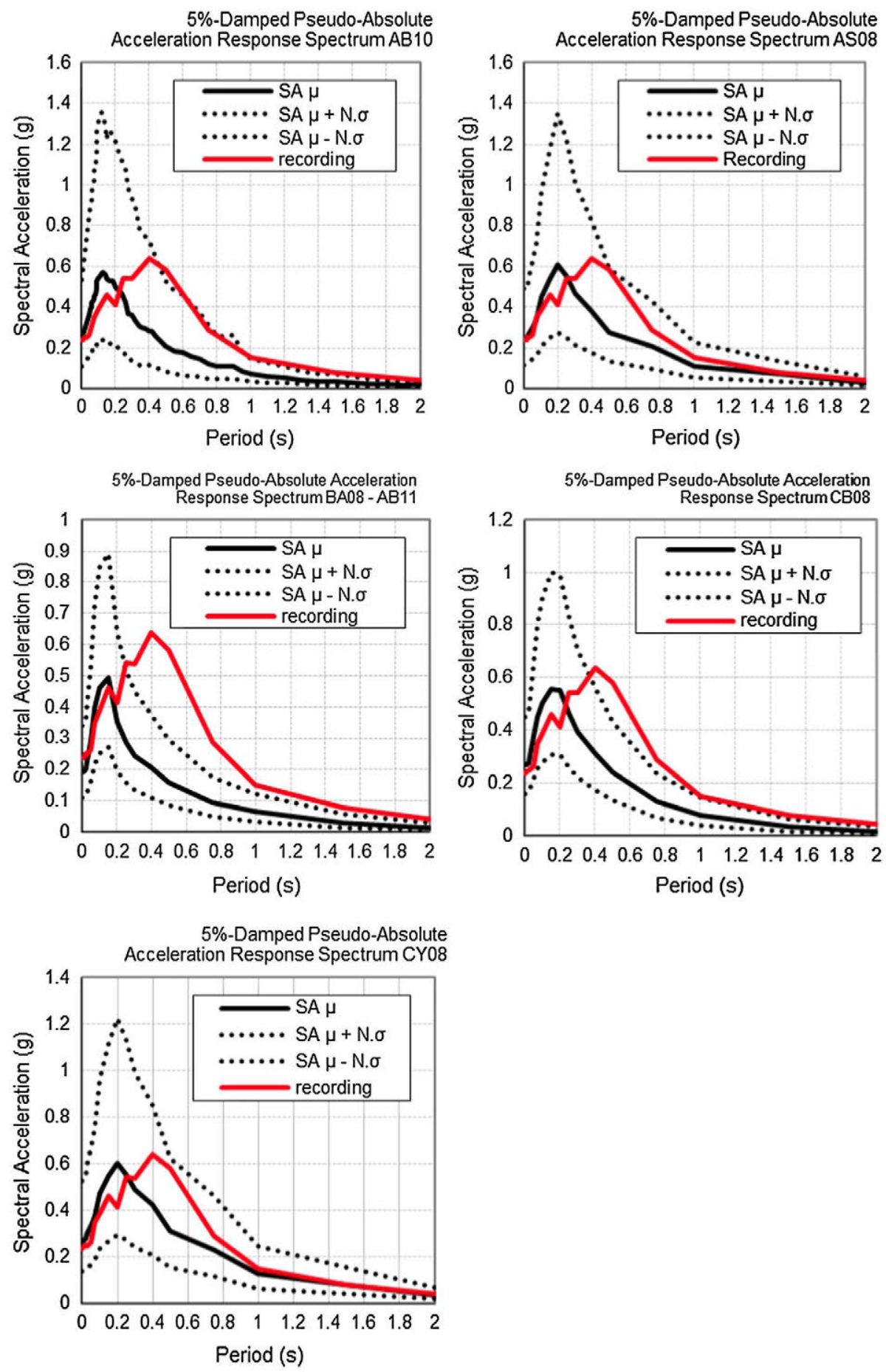

Fig. 2 Comparison between the response spectrum recorded at Lorca station and the ones predicted by the five GMPE used in this work. Factor $N$ represents the number of sigmas used in the GMPE estimates, in this case $\mathrm{N}=1$ 

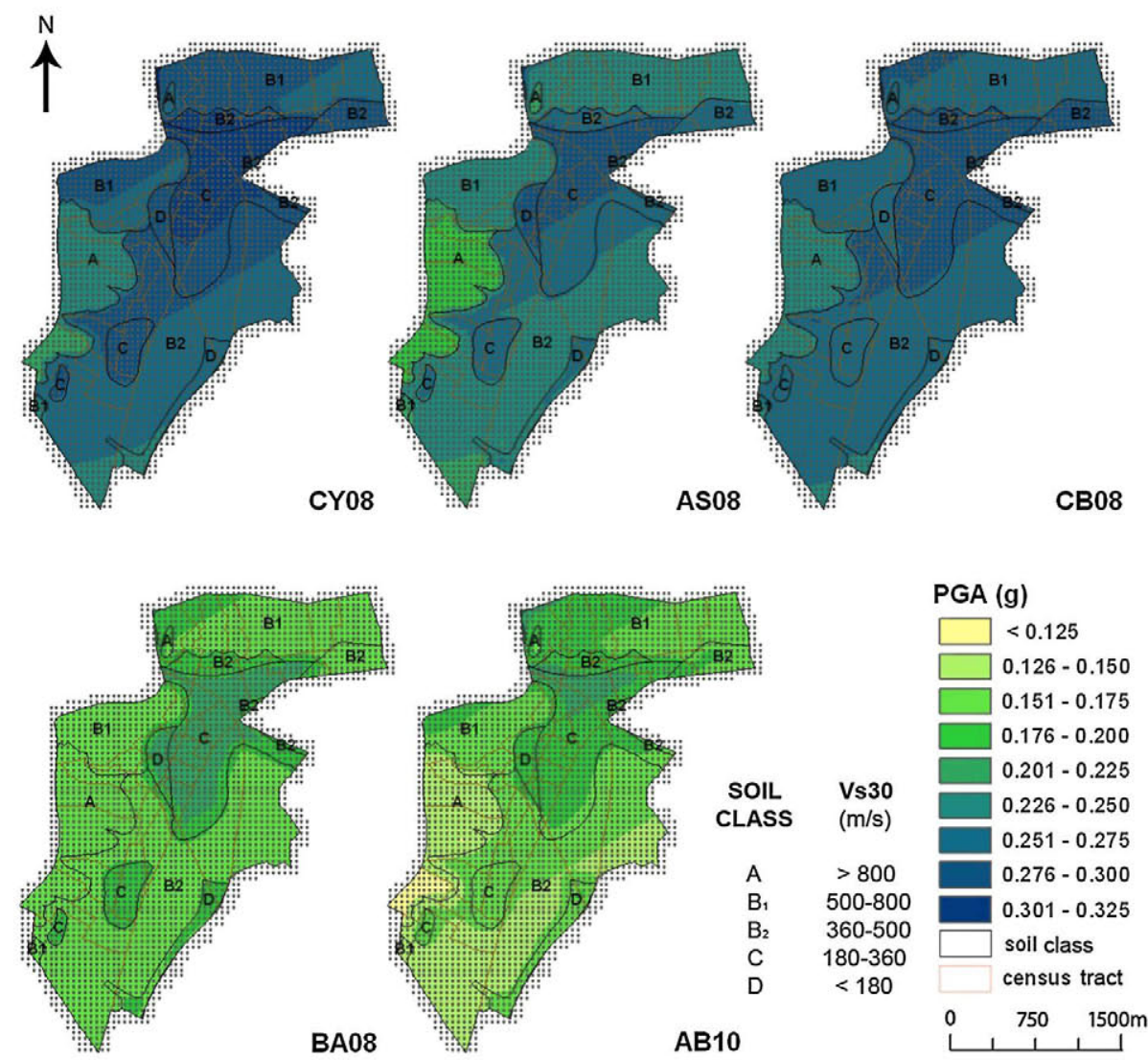

PGA (g)

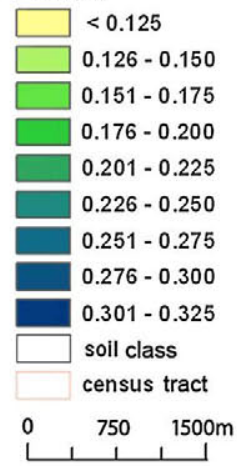

Fig. 3 Modeled PGA values (in g) using the five selected GMPEs for the city of Lorca, taking into account the source characteristics of the 2011 earthquake and the soil conditions in the different parts of the town of Navarro et al. (2013). Abrahamson and Silva (2008), Boore and Atkinson (2008) modified by Atkinson and Boore (2011), Campbell and Bozorgnia (2008) and Chiou and Youngs (2008)

\section{Modelling of seismic vulnerability and damage assessment}

Procedures for estimating the seismic vulnerability of different construction typologies can be classified as empirical, analytical and professional-judgement-based methods. The first ones involve statistical analyses using information of damage distribution and seismic performance of buildings in past earthquakes. The analytical methods use mechanically-derived expressions to describe the capacity of buildings to withstand the seismic demand and undergo different damage degrees. Recent studies (Lang 2012; Porter et al. 2012) describe and compare the existing methods applied in different parts of the world for vulnerability estimation. Some of the most utilized methodologies include: (1) the one implemented in HAZUS (FEMA/NIBS 1999), which is based on the ATC-38 (ATC 2000) data obtained from damage observations linked to important earthquakes occurred in the past time in the United States of America (2) analytical methods developed in the ATC-55 (ATC 2005) and the RISK-UE project (RISK-UE; Mouroux and Lebrun 2006) carried out for the European region. Applications and developments of these methodologies can be found in the SELENA software 

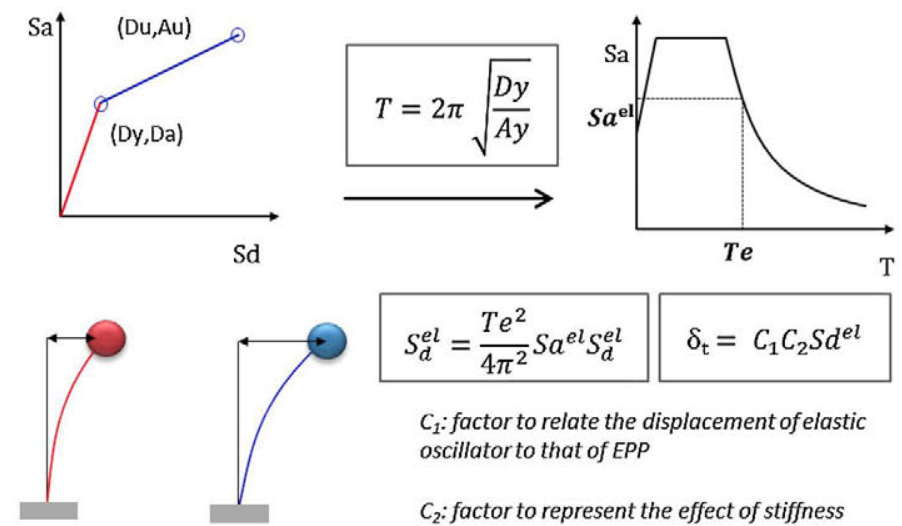

Elastic, Te

Inelastic, EPP

$S_{d}^{e l}=\frac{T e^{2}}{4 \pi^{2}} S a^{e l} S_{d}^{e l} \quad \delta_{\mathrm{t}}=C_{1} C_{2} S d^{e l}$

$C_{1}$ : factor to relate the displacement of elastic oscillator to that of EPP

$C_{2}$ : factor to represent the effect of stiffness degradation

Fig. 4 Scheme of the computation of the performance point using the I-DCM method

(Molina et al. 2010), Fajfar (1999) and the PAGER project (Jaiswal and D'Ayala 2011). The ATC-13 approach (ATC 1985) is based on expert-opinion and it is widely used because of its accessibility and large amount of capacity and vulnerability functions available. However, more recent methods, based on engineering procedures, have been developed in the ATC-58 project (ATC 2012).

In this study, analytical methods for the vulnerability and damage assessment are used because they are the best applicable way to estimate damage when the ground-motion is given in terms of spectral accelerations $S_{a}$ and spectral displacements $S_{d}$. In these methods, the behaviour of every building is represented by a capacity curve that relates its lateral displacement with different base accelerations. For a given building typology, the capacity curves are linked to the fragility curves, which represent the probability of the building of suffering different damage degrees. These fragility curves are modeled with a probabilistic log-normal distribution. The Hazus and RISK-UE methodologies (FEMA-440 2005; Milutinovic et al. 2003, respectively) contain specific capacity curves for different structural typologies. Lagomarsino and Giovinazzi (2006) present a study of calibration and standardisation of the Risk-UE curves for the European countries.

In order to assign the capacity curves that represent with the best accuracy the behaviour of the different construction typologies present in Lorca, the conclusions of Quiros et al. (2011) are followed. This study contains a comparative analysis of the capacity curves developed in HAZUS-MH (2003) and RISK-UE (Milutinovic et al. 2003) for application to the construction typologies present in Southeastern Spain. As a result of this study, the curves calibrated by Lagomarsino and Giovinazzi (2006) turned out to be most appropriate to represent the structural behaviour of the analysed typologies.

The capacity curves are related with demand spectra using one of the methods developed by the ATC-55, reported in the FEMA-440, which is the Improved Displacement Coefficient Method (I-DCM) (FEMA-440 2005), to obtain the performance point for each building vulnerability class (Fig. 4). This method has been updated from the Displacement Coefficient method originally proposed in the ATC-13 (ATC 1985), principally aimed to improve the accuracy of the peak SDOF displacement estimations (Akkar and Metin 2007).

Finally, entering with the performance point into the fragility curves, the probability of reaching a certain damage grade is estimated (Fig. 5). The damage grades described in the 


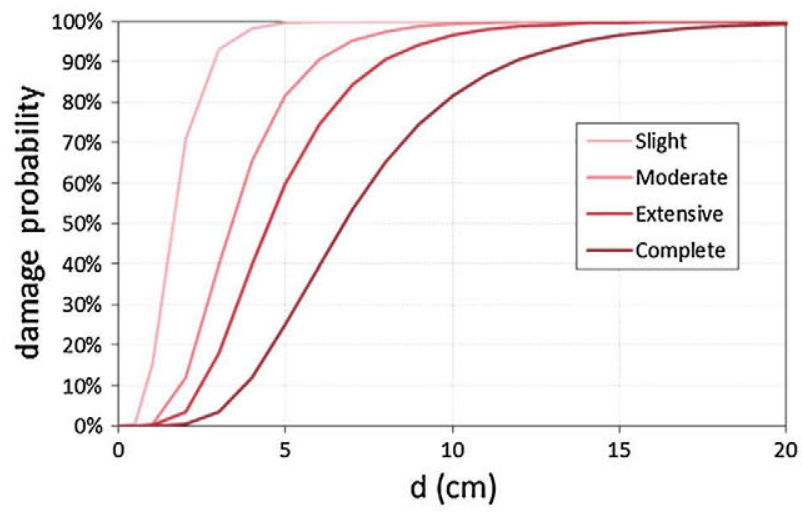

Fig. 5 Fragility curves for building type RC1M-pre, as an example of the ones used in this work

RISK-UE methodology (slight, moderate, extensive and complete, Milutinovic et al. 2003), are considered in this work. Following Lagomarsino and Giovinazzi (2006), whose work is based on the RISK-UE classification, the following levels of damage are established: slight refers to slight non-structural and none structural damage, moderate refers to moderate nonstructural and slight structural damage, extensive refers to heavy non-structural and moderate structural damage, and finally complete refers to very heavy non-structural, heavy and very heavy (destruction) structural damage.

\subsection{Cadastral database of Lorca}

Lorca is a historical city that presents a varied building stock, where construction typologies of different age and nature coexist. Thus, it is convenient to make a distinction between the behaviour of the traditional construction (masonry buildings) and the present-day reinforced concrete (RC) structures.

The building stock of Lorca is basically composed by four types of constructions (according to the Risk-UE classification): (1) stone masonry bearing walls, made of rubble stone, fieldstone (M1.1); (2) unreinforced masonry bearing walls with wooden slabs (M3.1); (3) unreinforced masonry bearing walls with reinforced concrete slabs (M3.4) and (4) reinforced concrete structures of concrete moment frames (RC1). These four building typologies are further subdivided, according to the number of floors, in low-rise, medium-rise and highrise; and according to the level of earthquake-resistant design established in the respective seismic codes in force along the years in pre-code (buildings built prior to 1964), low-code (low design level, with building date between 1964 and 1996) and moderate-code (medium level of seismic design, building date equal or later than 1997). At the end, a total of 14 building types ( 7 masonry and $7 \mathrm{RC}$ ) are distinguished, according to their seismic vulnerability. Table 3 shows the values that characterise the capacity and fragility curves that will be applied to these typologies. The total number of buildings erected in Lorca by 2008 was 6,797 , with a $76 \%$ of masonry and a $24 \%$ of reinforced concrete.

\subsection{Damage assessment}

In order to assess the damage to the built-up area of Lorca, due to the 2011 earthquake, the first step consists on defining the working scale. The working unit adopted in Lorca is the census tract (CT), finding a total of $35 \mathrm{CT}$ inside the town. The second step consists on assigning 
Table 3 Parameters defining the capacity and fragility curves of the building typologies used for damage modeling (after Lagomarsino and Giovinazzi 2006)

\begin{tabular}{|c|c|c|c|c|c|c|c|c|c|c|c|c|}
\hline \multirow[t]{2}{*}{ Typology } & \multicolumn{4}{|l|}{ Capacity } & \multicolumn{8}{|l|}{ Fragility } \\
\hline & Dy $(\mathrm{cm})$ & Ay $(\mathrm{g})$ & $\mathrm{Du}(\mathrm{cm})$ & $\mu$ & SMean $(\mathrm{cm})$ & SBeta & MMean $(\mathrm{cm})$ & MBeta & EMean $(\mathrm{cm})$ & EBeta & CMean $(\mathrm{cm})$ & CBeta \\
\hline M11L-pre & 0.19 & 0.168 & 0.89 & 4 & 0.133 & 0.61768 & 0.285 & 0.61768 & 0.54 & 0.6177 & 0.89 & 0.61768 \\
\hline M11M-pre & 0.42 & 0.133 & 1.35 & 3 & 0.294 & 0.46704 & 0.63 & 0.46704 & 0.885 & 0.467 & 1.35 & 0.46704 \\
\hline M31L-pre & 0.28 & 0.279 & 1.4 & 5 & 0.196 & 0.64378 & 0.42 & 0.64378 & 0.84 & 0.6438 & 1.4 & 0.64378 \\
\hline M31M-pre & 0.63 & 0.221 & 2.11 & 3 & 0.441 & 0.48349 & 0.945 & 0.48349 & 1.37 & 0.4835 & 2.11 & 0.48349 \\
\hline M34L-pre & 0.36 & 0.324 & 1.71 & 4 & 0.252 & 0.62326 & 0.54 & 0.62326 & 1.035 & 0.6233 & 1.71 & 0.62326 \\
\hline M34M-pre & 0.8 & 0.256 & 2.6 & 3 & 0.56 & 0.47146 & 1.2 & 0.47146 & 1.7 & 0.4715 & 2.6 & 0.47146 \\
\hline M34H-pre & 0.97 & 0.168 & 2.9 & 3 & 0.679 & 0.43807 & 1.455 & 0.43807 & 1.935 & 0.4381 & 2.9 & 0.43807 \\
\hline RC1M-pre & 2.24 & 0.124 & 6.74 & 3 & 1.568 & 0.44063 & 3.36 & 0.44063 & 4.49 & 0.4406 & 6.74 & 0.44063 \\
\hline RC1H-pre & 3.04 & 0.072 & 9.15 & 3 & 2.128 & 0.44076 & 4.56 & 0.44076 & 6.095 & 0.4408 & 9.15 & 0.44076 \\
\hline RC1L-low & 1.73 & 0.363 & 5.18 & 3 & 1.211 & 0.43867 & 2.595 & 0.43867 & 3.455 & 0.4387 & 5.18 & 0.43867 \\
\hline RC1M-low & 2.69 & 0.263 & 8.06 & 3 & 1.883 & 0.43895 & 4.035 & 0.43895 & 5.375 & 0.439 & 8.06 & 0.43895 \\
\hline RC1H-low & 3.82 & 0.185 & 11.47 & 3 & 2.674 & 0.43979 & 5.73 & 0.43979 & 7.645 & 0.4398 & 11.47 & 0.43979 \\
\hline RC1L-mod & 2.03 & 0.426 & 5.08 & 4 & 1.421 & 0.51467 & 3.045 & 0.51467 & 4.69 & 0.5147 & 7.35 & 0.51467 \\
\hline RC1M-mod & 2.88 & 0.282 & 7.2 & 4 & 2.016 & 0.56649 & 4.32 & 0.56649 & 7.375 & 0.5665 & 11.87 & 0.56649 \\
\hline
\end{tabular}

Dy, Ay displacement and acceleration in the yield point, $L$ low-rise, $M$ medium rise, $H$ high rise, pre pre-code, low low-code, $m o d$ moderate-code 


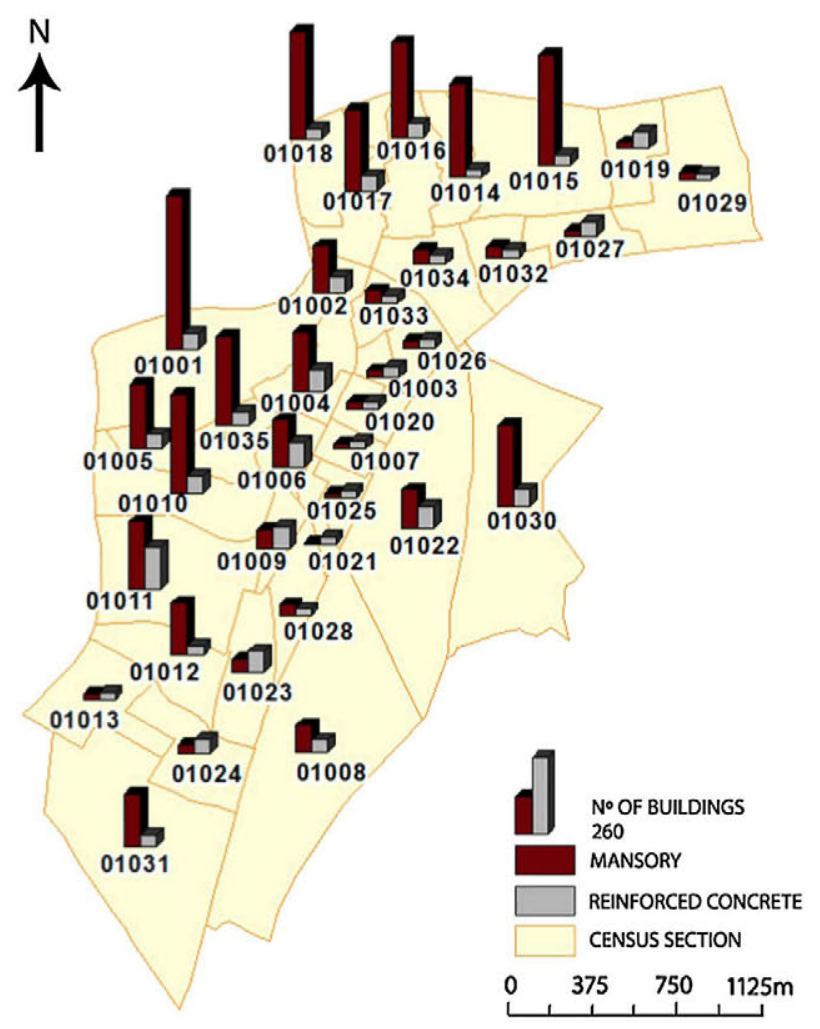

Fig. 6 Number of masonry and reinforced concrete buildings per census tract in Lorca

the number of buildings contained in each unit associated to the different building typologies considered (Fig. 6). After these two steps have been accomplished, the seismic vulnerability of Lorca will be assessed, giving the number of masonry and reinforced concrete buildings in every $\mathrm{CT}$.

The inclusion of the input seismic action is carried out through the average specific response spectra of every CT. These spectra have been estimated from the predicted values of PGA and SA(T) for periods $\mathrm{T}$ of $0.1,0.2,0.3,0.4,0.5,1.0$ and $2.0 \mathrm{~s}$. For each of these spectra, the maximum demand displacement is calculated using the I-DCM method, in order to obtain the probabilities of the five damage grades described in RISK-UE.

As an example, Table 4 shows, the percentages of each damage level (none, slight, moderate, extensive and complete) that the different construction typologies displays in one of the CT (referenced as 01001). The table illustrates how masonry buildings would remain severely damaged with the combination of GMPEs and capacity curves of CY08 \& LG06, CB08 \& LG06 and AS08 \& LG06. Specifically, typology M11L-pre reaches $90 \%$ in extensive and complete damage. The percentage of extensive and complete damage of the reinforced concrete structures is very low for all analysed GMPEs; in particular the combination of BA08 \& LG06 and AB10 \& LG06 show no damage in over $97 \%$.

The specific damage percentages for each CT have been multiplied by the number of buildings of the respective typologies. The damage scenarios are thus established as an estimate of buildings that would remain affected with five different damage levels in each census tract of the city. 
Table 4 Damage probabilities for the building typologies analyzed in one of the census tracts of Lorca (01001) for the five GMPEs considered

\begin{tabular}{|c|c|c|c|c|c|c|c|c|c|c|c|c|c|c|c|c|c|c|c|c|c|c|c|c|c|}
\hline \multirow[t]{2}{*}{ Typology } & \multicolumn{5}{|c|}{ CY08 \& LG06 } & \multicolumn{5}{|c|}{ AS08 \& LG06 } & \multicolumn{5}{|c|}{ CB08 \& LG06 } & \multicolumn{5}{|c|}{ BA08 \& LG06 } & \multicolumn{5}{|c|}{ AB10 \& LG06 } \\
\hline & $\% \mathrm{~N}$ & $\% \mathrm{~S}$ & $\% \mathbf{M}$ & $\% \mathrm{E}$ & $\% \mathrm{C}$ & $\% \mathrm{~N}$ & $\% \mathrm{~S}$ & $\% \mathrm{M}$ & $\% \mathrm{E}$ & $\% \mathbf{C}$ & $\% \mathrm{~N}$ & $\% \mathrm{~S}$ & $\% \mathrm{M}$ & $\% \mathrm{E}$ & $\% \mathrm{C}$ & $\% \mathrm{~N}$ & $\% \mathrm{~S}$ & $\% \mathbf{M}$ & $\% \mathrm{E}$ & $\% \mathrm{C}$ & $\% \mathrm{~N}$ & $\% \mathrm{~S}$ & $\% \mathrm{M}$ & $\% \mathrm{E}$ & $\% \mathrm{C}$ \\
\hline M11L-pre & 0 & 1 & 8 & 20 & 71 & 0 & 1 & 8 & 20 & 71 & 0 & 2 & 14 & 27 & 56 & 4 & 26 & 40 & 21 & 9 & 2 & 18 & 38 & 26 & 16 \\
\hline M11M-pre & 0 & 5 & 12 & 31 & 52 & 0 & 6 & 15 & 33 & 46 & 0 & 13 & 22 & 35 & 30 & 10 & 54 & 22 & 12 & 2 & 7 & 49 & 25 & 16 & 4 \\
\hline M31L-pre & 1 & 13 & 36 & 29 & 21 & 1 & 13 & 36 & 29 & 21 & 3 & 20 & 40 & 24 & 14 & 24 & 44 & 26 & 5 & 1 & 17 & 42 & 31 & 8 & 2 \\
\hline M31M-pre & 2 & 27 & 29 & 28 & 13 & 2 & 31 & 30 & 26 & 11 & 5 & 43 & 28 & 18 & 5 & 39 & 52 & 8 & 2 & 0 & 27 & 56 & 13 & 4 & 0 \\
\hline M34L-pre & 3 & 23 & 40 & 23 & 11 & 3 & 23 & 40 & 23 & 11 & 6 & 31 & 39 & 18 & 7 & 34 & 45 & 17 & 3 & 0 & 26 & 46 & 23 & 4 & 1 \\
\hline M34M-pre & 5 & 44 & 27 & 18 & 5 & 7 & 48 & 26 & 16 & 4 & 13 & 56 & 20 & 9 & 2 & 56 & 40 & 3 & 1 & 0 & 48 & 46 & 5 & 1 & 0 \\
\hline M34H-pre & 6 & 52 & 22 & 16 & 4 & 9 & 56 & 20 & 12 & 2 & 33 & 57 & 7 & 2 & 0 & 76 & 24 & 1 & 0 & 0 & 82 & 17 & 0 & 0 & 0 \\
\hline RC1M-pre & 39 & 54 & 6 & 2 & 0 & 47 & 48 & 4 & 1 & 0 & 84 & 16 & 0 & 0 & 0 & 95 & 5 & 0 & 0 & 0 & 100 & 0 & 0 & 0 & 0 \\
\hline RC1H-pre & 34 & 57 & 7 & 2 & 0 & 41 & 52 & 5 & 1 & 0 & 92 & 7 & 0 & 0 & 0 & 98 & 2 & 0 & 0 & 0 & 100 & 0 & 0 & 0 & 0 \\
\hline RC1L-low & 48 & 48 & 4 & 1 & 0 & 55 & 42 & 3 & 1 & 0 & 75 & 25 & 1 & 0 & 0 & 97 & 3 & 0 & 0 & 0 & 99 & 1 & 0 & 0 & 0 \\
\hline RC1M-low & 63 & 35 & 2 & 0 & 0 & 70 & 28 & 1 & 0 & 0 & 93 & 6 & 0 & 0 & 0 & 99 & 1 & 0 & 0 & 0 & 100 & 0 & 0 & 0 & 0 \\
\hline RC1H-low & 81 & 18 & 0 & 0 & 0 & 86 & 14 & 0 & 0 & 0 & 99 & 1 & 0 & 0 & 0 & 100 & 0 & 0 & 0 & 0 & 100 & 0 & 0 & 0 & 0 \\
\hline RC1L-mod & 60 & 36 & 4 & 0 & 0 & 66 & 31 & 3 & 0 & 0 & 81 & 18 & 1 & 0 & 0 & 97 & 3 & 0 & 0 & 0 & 99 & 1 & 0 & 0 & 0 \\
\hline RC1M-mod & 65 & 31 & 4 & 0 & 0 & 70 & 27 & 3 & 0 & 0 & 90 & 9 & 0 & 0 & 0 & 98 & 2 & 0 & 0 & 0 & 99 & 1 & 0 & 0 & 0 \\
\hline
\end{tabular}



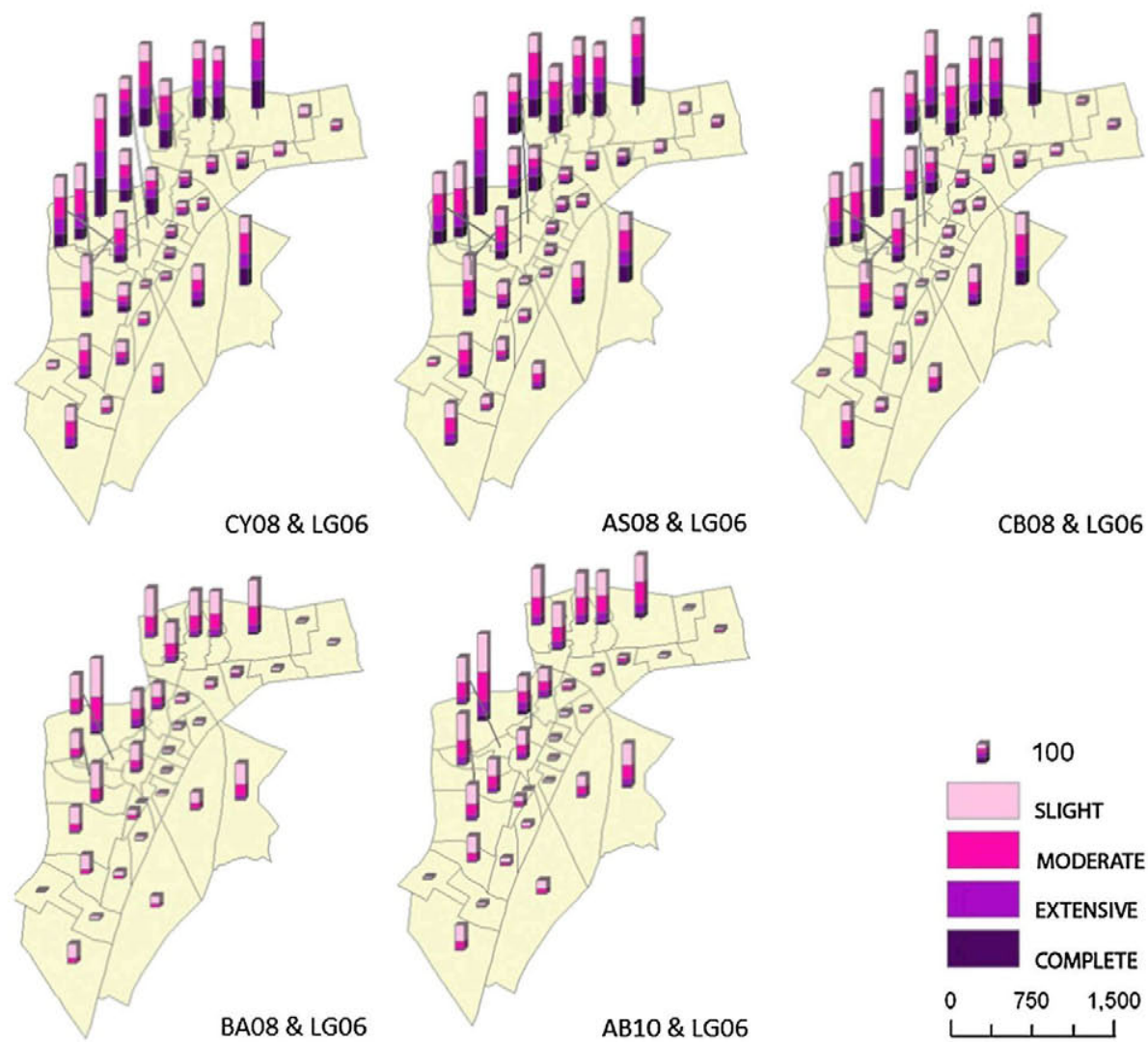

CB08 \& LG06

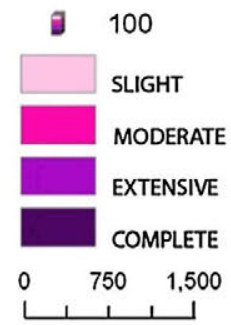

Fig. 7 Damage scenarios modeled for the five GMPEs and the capacity and fragility curves of Lagomarsino and Giovinazzi (2006)

These damage scenarios have been worked out considering as seismic input the results given by the different selected strong motion models for each CT. Figure 7 illustrates those scenarios, showing that the most severe modelled damage with the five GMPEs appears in the CT located in the north-western part of the city. This can be explained by two factors that mainly occur in those census tracts: the high accelerations estimated, as a result of their proximity to the source and the site effects (Fig. 3) and, to a greater extent, to the large amount of highly vulnerable masonry buildings (Fig. 6). The AS08 \& LG06, CB08 \& LG06 and CY08 \& LG06 combinations present a greater seismic damage, with more than 100 buildings with extensive and complete damage in several CT.

The comparison of distributions between the expected damage and vulnerability shows a clear correlation between them. Additionally, the relative damage distribution in the city is very similar to the exposure distribution (number of buildings per census tract).

\section{Earthquake damage database}

The damage assessment carried out in Lorca after the 2011 earthquake was led by the Civil Defence Department (Office of the Government Delegate, Murcia). Building damage was 


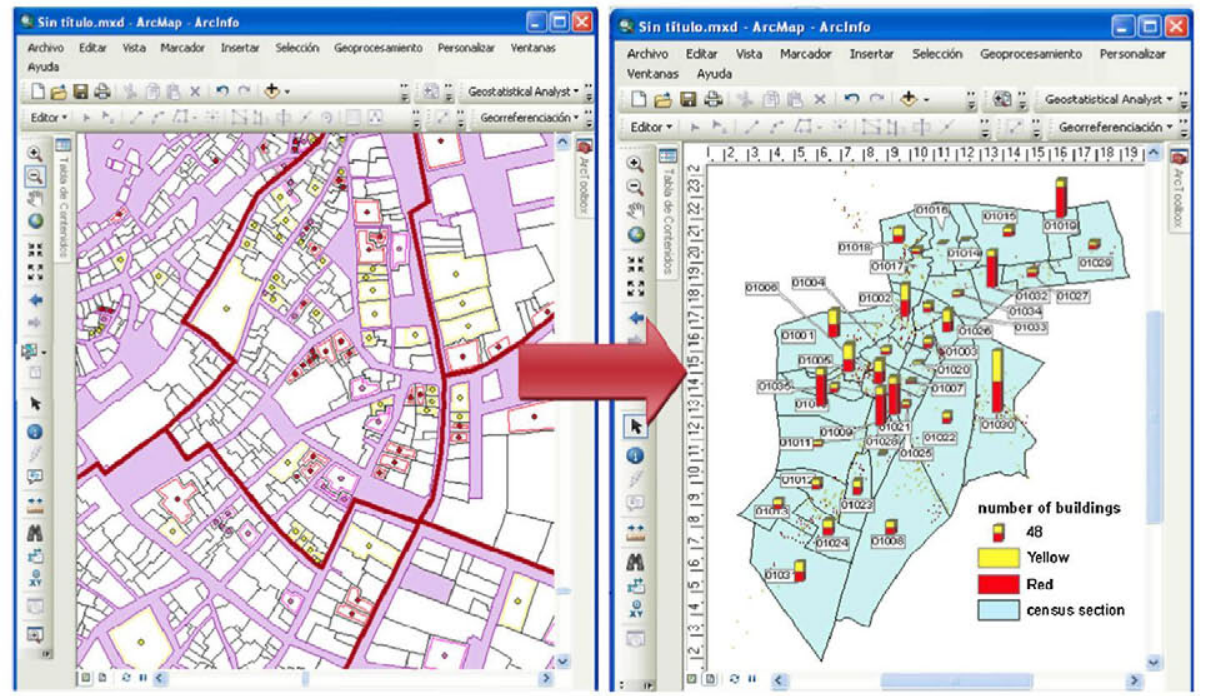

Fig. 8 Database of reported damage in Lorca used in this study (left). Building grouping per census tract (right)

classified into a four-colour code: Black, Red, Yellow and Green. This code was established primarily based on habitability and safety criteria and they can be described as follows:

- Black colour marks that a building has collapsed or that it presents extreme structural damage, so its demolition is advised.

- Red indicates that the building has undergone severe structural damage and it has lost its bearing capacity so there is a significant chance of collapse if additional shaking (as caused by an aftershock) occurs. Evacuation of the building and of adjacent areas should be contemplated to prevent secondary damage. Underpinning and eventually demolition should be considered.

- Yellow designates buildings that present a significant reduction of their bearing capacity or that have suffered important damage to architectural elements. Their occupation is conditioned to the removal or reparation of the components that may fall down and the reparation of structural elements which are moderately damaged.

- Green is used for buildings that do not show any apparent loss of bearing capacity and only present minor damage to architectural elements which can be easily fixed and that do not imply any threat.

A geo-referencing process is developed to assign a number of buildings with different degrees of damage to each census tract. Figure 8 shows the damage distribution, where the buildings classified as black and red have been grouped and represented together as red.

The analysis of the damage in Lorca after the 2011 earthquake indicates that about $80 \%$ of the buildings underwent damage of varying degrees, from slight to complete. The greatest degree of damage concentrates in the Barrio de La Viña and the Barrio de San Diego. A quick estimation of habitability on 7,862 buildings shows one building collapsed, $5 \%$ Black, $8 \%$ Red, $19 \%$ Yellow and $68 \%$ Green.

According to the architect Patrick Murphy (Lorca earthquake report IGN 2011), the damage produced in Lorca in the masonry buildings under the seismic action follows a recognised, widely studied pattern. Wall planes subjected to shear stresses are damaged by characteristic 

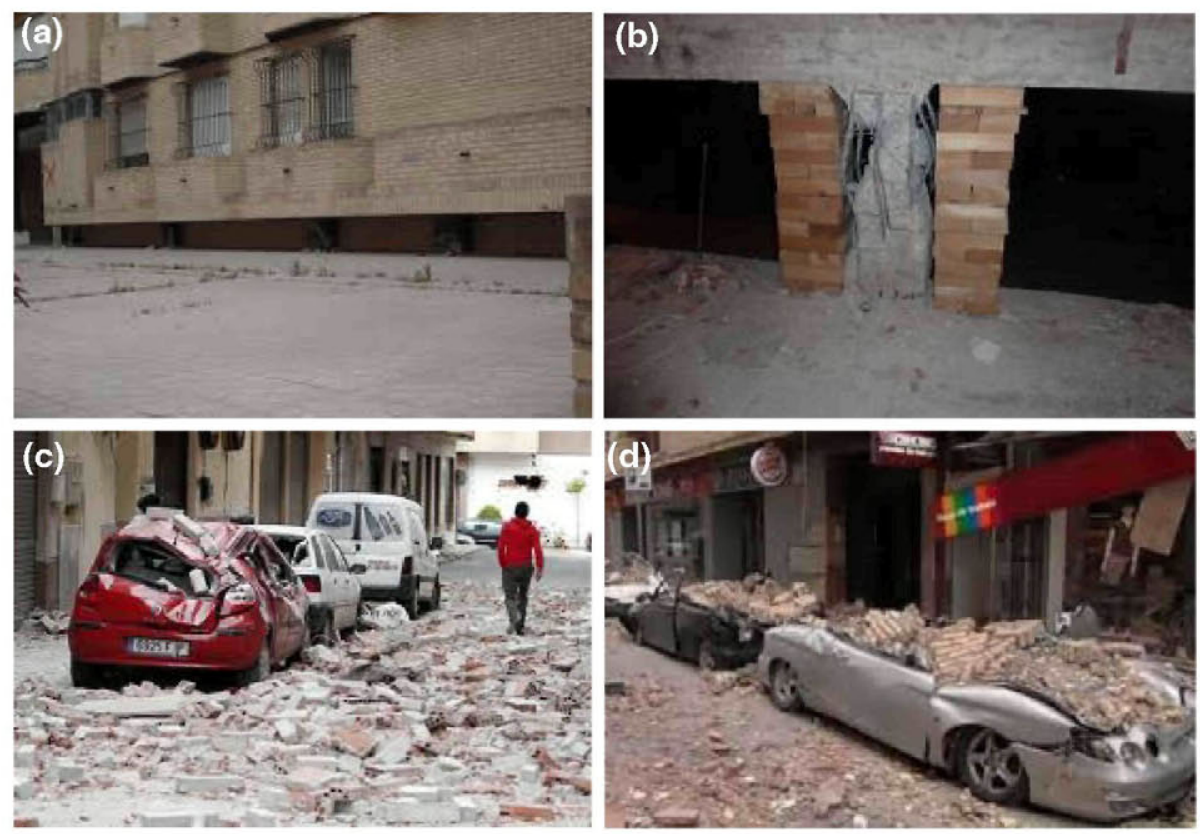

Fig. 9 Deformation on ground floors due to short column causing large structural damage, leading to building collapse (a, b). Detachment of ledges and parapets in the crowning of buildings (c, d)

X-shaped cracks while out-of-plane wall structures undergo drift and loss of juncture with the perpendicular strut walls.

The typology best describing the present-day construction in Lorca is a reinforced concrete structure with moment frames. This constructive solution relies on modular rigid frames for horizontal forces, and does not use neither structural wall system nor diagonal bracing so the changes in rigidity are not corrected. This occurs particularly in diaphanous ground floors planned for a commercial use. The combination of a relatively high ground floor and the absence of non-structural elements in the ground floor such as internal subdividing partition walls may lead to a relatively weak ground floor with respect to densely subdivided floors above with lower height, shear strength on pillar heads and inadequate confinement. Besides, the short pillars cause great structural damage in buildings up to the point of collapse. A masonry enclosure may modify the geometry of a pillar during an earthquake by limiting its deformation capacity (Fig. 9a, b).

Another very important aspect to take into account in Lorca is the detachment of barriers and ledges that we are the primary cause of mortality during the earthquake. Brick fabric ledges, barriers and parapets in the crowning of buildings are flung to the streets shattering cars and killing passers-by (Fig. 9c, d).

\section{Comparison and results}

To compare the distribution of observed damage in different parts of Lorca after the 2011 earthquake (Fig. 8) with the different distributions resulting from the different models (Fig. 7), a correspondence between the RISK-UE damage classification [as described by Lagomarsino and Giovinazzi (2006)] and the colour code used by the Civil Defence Department, need to 
Table 5 Comparison between the percentages of observed and modeled buildings labeled as Green, Yellow and Red plus Black

\begin{tabular}{lllc}
\hline & \multicolumn{3}{l}{ Percentage of buildings per damage degree } \\
\cline { 2 - 4 } & Green (\%) & Yellow (\%) & Red-Black (\%) \\
\hline Observed & 79 & 13 & 8 \\
CY08 \& LG06 & 59 & 19 & 21 \\
AS08 \& LG06 & 61 & 18 & 20 \\
CB08 \& LG06 & 70 & 16 & 14 \\
BA08 \& LG06 & 92 & 6 & 2 \\
AB10 \& LG06 & 88 & 8 & 4 \\
\hline
\end{tabular}

be established. According to the description of the effects over structural elements, black and red colours are related to the complete damage level, yellow is associated to the extensive damage level and green to moderate and slight damage levels.

Table 5 shows a summary of the percentages of buildings identified as Green, Yellow and Red plus Black after the earthquake and the modelling with the five GMPEs. By analysing these percentages, it may be appreciated that the AS08\&LG06 and CY08\&LG06 combinations simulate scenarios with higher expected damage than the observed one, while BA08\&LG06 and AB10\&LG06 present scenarios with lesser damage (less than 10\% of buildings marked as yellow, red and black). The model that seems to reproduce better the overall observed damage distribution is CB08\&LG06.

Figure 10 shows the distribution of the damage predicted by the five models together with the observed damage after the 2011 main shock for the extensive (yellow) and complete (red plus black, in the figure represented collectively in red) damage levels only. The distribution of observed damage within the city is different than the distributions resulting from the models. The predicted damage estimates are higher than the observed ones in the northern and western census tracts of the city. The opposite occurs in several census tracts of the eastern part of the city (such as 01019,01032,01021 and 01009), where the observed amount of damaged buildings is higher than the predicted ones. These differences reveal that the fragility curves fail at reproducing some specific factors that control the damage distribution at some locations.

\section{Discussion and conclusions}

The aim of this work was to calibrate some input models for the estimation of urban seismic risk in Spain in terms of expected damage distribution, using recorded and observed data from the Lorca, 2011 earthquake. Regarding the expected ground motion, the calibration was carried out with several GMPEs of the first NGA models (CY08, CB08, AS08 and BA08 models) and another GMPE based on data from stations located in Europe and the Middle East (AB10). The five selected models provide different ground motion estimates in Lorca: models CY08, AS08 and CY08 provide much higher ground motion estimates than models $\mathrm{AB} 10$ and BA08. These five models are combined with the capacity and fragility curves of LG06, in order to simulate the expected damage linked to the ground motion given by the GMPEs used. Separated analyses considering either the study area as a whole, either observing the subdivisions of Lorca in census tracts, are pertinent.

Taking the study area as a whole, out of the five model considered, the CB08\&LG06 model yields the closest damage estimates to the actual observations. The percentage of 


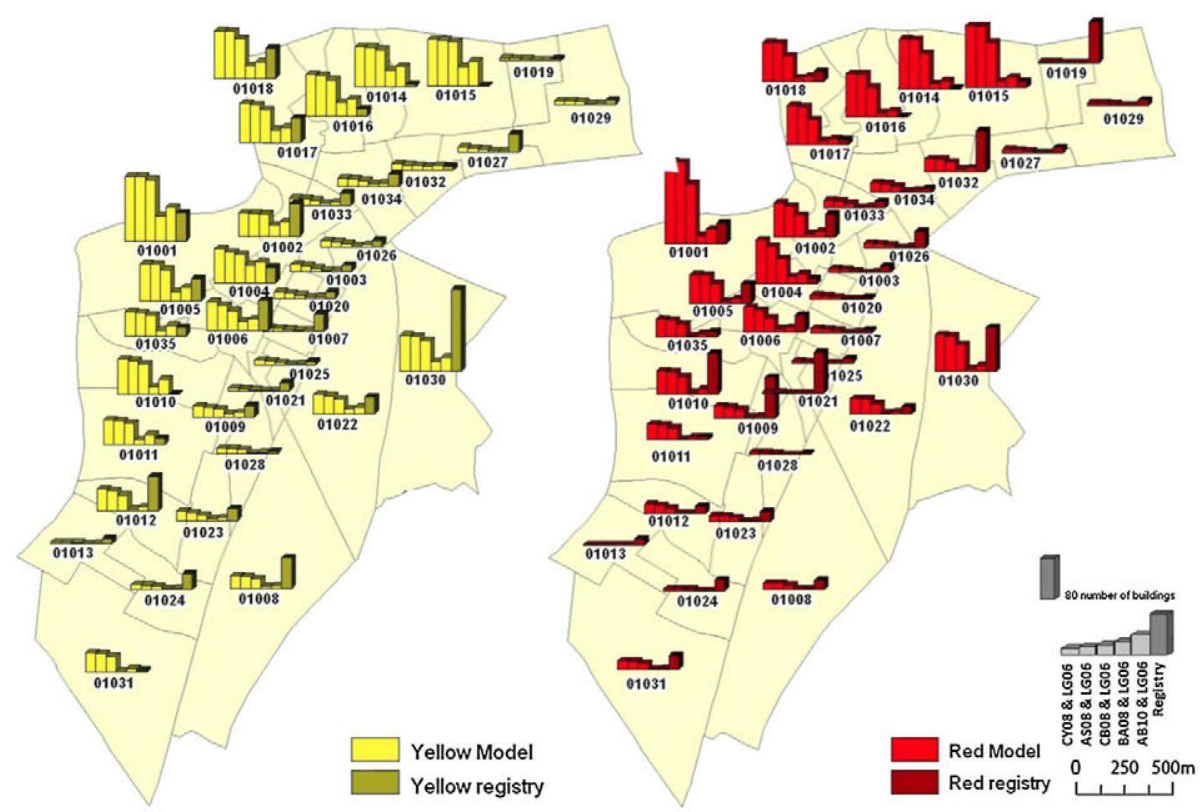

Fig. 10 Comparison between observed and predicted damage distribution (buildings labeled as red and yellow) using the five selected GMPEs and the capacity and fragility curves of Lagomarsino and Giovinazzi (2006). The representation unit is the census tract

buildings that remain classified as yellow and red was very similar to the one offered by this combination.

Considering the detailed scale, the modelled damage distribution reflects that the largest damage is located along the census tracts of the north-western part of the city. This can be attributed to several factors, such as the proximity of these census tracts to the earthquake source and to the predominance of masonry building typologies in these areas, which are more vulnerable than RC typologies. The lowest damage estimates are predicted in the census tracts located in the central part of the city, were RC buildings are more abundant. Thus, all models show a significant difference on predicted damage estimates between the north-western and central parts of Lorca.

This pattern is not appreciated in the actual damage distribution resulting from the 2011 event. The damage observed in the census tracts where masonry buildings are predominant (north-west Lorca) is not as large as the models predict, and the damage appreciated in the census tracts with more $\mathrm{RC}$ buildings (Lorca centre) is larger the predicted estimates. This may be explained by the exclusion in the calculations of some factors that enhance significantly building vulnerability (particularly applicable to RC buildings) and lead to higher observed damage, such the effects of short columns and diaphanous ground floors. These results claim some correction factors in the fragility curves in order to decrease the expected damage in masonry buildings and increase it in RC.

Summing up, modelling results do not fit totally well the actual damage distribution in the census tracts. None of the models used would reproduce completely the actual damage, because the observed damage distribution is much more variable and heterogeneous than the modelled damage distribution and the models used for the simulation do not include some important factors increasing or decreasing vulnerability. This implies that the aforementioned 
identification of the combination CB08\&LG06 as the one that best reproduces the damage estimates may be not correct for specific census tracts, and could be just the result of the combination of relatively high input ground motions with relatively low expected damages, which averages out the variations found at a more detailed scale, i. e., when considering census tracts. Accordingly, if the capacity and fragility curves used would account for factors such as short pillars and soft ground floor, then the expected damage for the same ground motion would increase, and a GMPE providing lower input accelerations (such as AB10) would lead to more realistic damage distribution estimates. To achieve this result, a more complete building stock database that includes data on soft stories and short pillars would be required.

Future directions for improving the present study can be stated. The first one refers to the input ground motions used. The NGA models adopted include a fairly complete description of the seismic source and the ground motion amplification factors due to site effects used for Lorca correspond to a recent and complete study (Navarro et al. 2013). However, the assessment of two factors may be improved: one is the rupture directivity effect (which in Lorca played an important role; Santoyo 2013) and the basin structure, which influence site effect estimates. The availability of the NGA west 2 project results would contribute to improve this point in the future.

A better constraint of the vulnerability model could be achieved with the inclusion of factors addressing short column and soft ground floor effects. A more complete database of the building stock of Lorca is required for this purpose. This would involve a significant work including field campaigns and revision of cadastral databases.

Finally, the translation of damage assessments performed right after the earthquake, which were primarily based on habitability conditions, to damage the scale used in this paper is done with a general procedure that does not take into account the particularities of each original damage assessment. This could lead to discrepancies between the distribution of damaged buildings used in this study and the actual seismic damage observed in 2011. A one-by-one revision of each original building damage report would be required to ascertain the most realistic damage estimates after the 2011 Lorca earthquake.

Acknowledgments The authors wish to thank two anonymous referees for their constructive and meaningful reviews. Funding from the Spanish Ministry of Science and Innovation ( $\mathrm{R}+\mathrm{D}$ National Plan, Project Asperides, reference CGL2009-14405-C02-01) is acknowledged. Fruitful discussions, comments and data from M. A. Santoyo (U. Complutense Madrid) and M. Navarro (U. Almeria) are highly appreciated.

\section{References}

Abrahamson NA, Silva WJ (2008) Summary of the Abrahamson \& Silva NGA ground motion relations. Earthq Spectra 24:67-97

Akkar S, Bommer JJ (2010) Empirical equations for the prediction of PGA, PGVand spectral accelerations in Europe, the Mediterranean and the Middle East. Seismol Res Lett 81(2):195-206

Akkar S, Metin A (2007) Assessment of improved nonlinear static procedures in FEMA-440. J Struct Eng 133(9):1237-1246

ATC-13: earthquake damage evaluation data for California,(1985) Applied Technology Council. Redwood City, CA

Atkinson GM, Boore DM (2011) Modifications to existing groundmotion prediction equations in light of new data. Bull Seismol Soc Am 101(3):1121-1135

Beauval C, Tasan H, Laurendeau A, Delavaud E, Cotton F, Guéguen P, Kuehn N (2012) On the testing of ground-motion prediction equations against small-magnitude data. Bull Seismol Soc Am 102(5): 19942007

Benito B, Gaspar-Escribano JM (2007) Ground motion characterization in Spain: context, problems and recent developments in seismic hazard assessment. J Seismol 11:433-452 
Benito B, Navarro M, Vidal F, Gaspar-Escribano JM, García MJ, Martínez-Solares JM (2010) A new seismic hazard assessment in the region of Andalusia (Southern Spain). Bull Earthq Eng 8:739-766

Benito B, Capote B, Murphy P, Gaspar-Escribano JM, Martínez-Díaz JJ, Tsige M, Stich D, García-Mayordomo J, García MJ, Jiménez ME, Insua-Arévalo JM, Álvarez-Gómez JA, Canora C (2007) An overview of the damaging and low magnitude La Paca earthquake (Mw 4.8) on January 29th, 2005. Context; seismotectonics; and seismic risk implications for South East Spain. Bull Seismol Soc Am 97:671-690

Benito B, Gaspar-Escribano JM, Martínez-Díaz JJ, García Rodríguez MJ, Jiménez Peña E, Canora C, ÁlvarezGómez JA (2008) The RISMUR Project: Seismic Risk assessment of the Murcia province (SE Spain). Bolletino di Geofisica Teorica e Applicata 49(1):3-15

Boore DM, Atkinson GM (2008) Ground motion prediction equations for the average horizontal component of PGA, PGV, and 5\%-Damped PSA at spectral periods between 0.01 s and 10.0 s. Earthq Spectra 24:99-138

Cabañas L, Alcalde JM, Carreño E, Bravo JB (2013) Characteristics of observed strong motion accelerograms from the 2011 Lorca (Spain) Earthquake. Bull Earthquake Eng. doi:10.1007/s10518-013-9501-0

Campbell KW, Bozorgnia Y (2008) NGA ground motion model for the geometric mean horizontal component of PGA, PGV, PGD and 5\%-damped linear elastic response spectra for periods ranging from 0.01 to $10 \mathrm{~s}$. Earthq Spectra 24:139-171

Chiou BS-J, Youngs RR (2008) An NGA model for the average horizontal component of peak ground motion and response spectra. Earthq Spectra 24:173-215

Chiou BS-J, Youngs RR, Abrahamson NA, Addo K (2010) Ground-motion attenuation model for smalltomoderate shallow crustal earthquakes in California and its implications on regionalization of ground motion prediction models. Earthq Spectra 26:907-926

Delavaud E, Cotton F, Akkar S, Scherbaum F, Danciu L, Beauval C, Drouet S, Douglas J, Basili R, Sandikkaya MA, Segou M, Faccioli E, Theodoulidis N (2012a) Toward a ground-motion logic tree for probabilistic seismic hazard assessment in Europe. J Seismol 16:3-451

Delavaud E, Scherbaum F, Kuehn N, Allen T (2012b) Testing the global applicability of ground-motion prediction equations for active shallow crustal regions. Bull Seismol Soc Am 102(2):707-721

Fajfar P (1999) Capacity spectrum method based on inelastic demand spectra. Earthq Eng Struct Dyn 28:979993

FEMA-NIBS (1999) HAZUS: Userss Manual and Technical Manuals, vols 1-3 (4 vols). Federal Emergency Management Agency and Institute of Building Sciences, Washington, DC.

FEMA-440 (2005) Improvement of nonlinear static seismic analysis procedures. Technical report. Applied Technology Council (ATC), CA, USA, pp 392.

Gaspar-Escribano JM, Benito B, Rivas-Medina A (2011) Nuevo estudio de peligrosidad sísmica en Navarra. Memory of $4^{\circ}$ Congreso Nacional de Ingeniería Sísmica. Granada.

Jaiswal KS, D'Ayala Wald DJ (2011) Developing empirical collapse fragility functions for global building types. Earthq Spectra 3(27):775-795

Lagomarsino S, Giovinazzi S (2006) Macroseismic and mechanical models for the vulnerability and damage assessment of current buildings. Bull Earthq Eng 4:415-443

Lang DH (2012) Earthquake damage and loss asssesment-predicting the unpredictable. University of Bergen, Bergen

Lorca report IGN (2011) Informe del sismo de Lorca del 11 de mayo de 2011 . www.ign.es.

Milutinovic ZV, Trendafiloski GS (2003) An advanced approach to earthquake risk scenarioswith applications to different European towns. WP4: Vulnerability of current buildings, pp 110.

Molina S, Lang DH, Lindholm CD, and Lingvall F (2010) User manual for the earthquake loss estimation tool: SELENA. NORSAR, Kjeller Norway. http:/www.riesgosismico.es/selenamanual.pdf [viewed 30 Apr 2012]

Mouroux P, Lebrun B (2006) Presentation of RISK-UE Project. Bull Earthq Eng 4(4):323-339 (special issue: earthquake scenarios for European cities).

Navarro M, García-Jerez A, Alcalá FJ, Vidal F, Enomoto T (2013) Local site effect microzonation of Lorca town (southern Spain) (this issue).

Porter KA, Jaiswal KS, Wald D, D’Ayala D, Meslem A, So E, Kiremidjian AS, Noh HY (2012) Global vulnerability estimation methods for the global eartquake model. 15WCEE, Lisbon 2012.

Quiros LE, Torres Y, Erduran E, Benito B, Navarro M (2011) Asignación de curvas de capacidad y fragilidad a las tipologías estructurales típicas del sureste de España. Proceedings of $4^{\circ}$ Congreso Nacional de Ingeniería Sísmica. Granada.

Santoyo MA (2013) Finite fault analysis and near field dynamic strains and rotations due to the 11/05/2011 (Mw5.2) Lorca Earthquake, South-Eastern Spain (this issue). 
